\title{
Observation of the Therapeutic outcome of Local Block with Promethazine and Routine Surgery in the Treatment of Popliteal Cyst
}

X. CHEN, Y. ZUO'1, P. LI', G. LIN¹, H. WANG ${ }^{1}$, F. SHEN¹ AND Z. YIN*

${ }^{1}$ Graduate School, Anhui Medical University, Hefei 230022, ${ }^{1}$ Department of Orthopedics, Fuzhou General Hospital of Nanjing Military Command, Putian 351100, China

Chen et al: Promethazine and Routine Surgery in the Treatment of Popliteal Cyst 
To analyze the therapeutic efficacy of local block with promethazine and routine surgery in the treatment of popliteal cyst and explore the clinical efficacy of arthroscopy-assisted modified popliteal cyst resection therapy, a total of 116 patients with popliteal cyst treated at the Fuzhou General Hospital of Nanjing Military Command were enrolled. These patients were divided into the control group, who underwent routine surgery and the research group, who were subjected to local block with promethazine, with 58 patients in each group. The therapeutic efficacy was observed and compared. The incision length and surgical time of the research group were significantly lower than that of the control group. By comparing the remission rates of clinical symptoms at $2 \mathrm{~d}, 1 \mathrm{mo}, 2 \mathrm{mo}$ and $1 \mathrm{y}$ after surgery, the magnetic resonance imaging data, the recovery rate and recurrence rate, results showed that the research group had greater advantage over the control group $(\mathbf{P}<\mathbf{0 . 0 5})$. Local block with promethazine could produce ideal outcomes in the treatment of popliteal cyst than routine surgery.

Key words: Promethazine, local block, arthroscopy-assisted modified approach, popliteal cyst, routine surgery

Popliteal cyst, also known as Baker's cyst, is caused by the accumulation of synovial fluid in the tendon sheath behind the knee joint. Generally, no pain is complained in children with popliteal cyst. But there is obvious swelling behind the knee when the knee is fully extended. However, the swelling behind the knee is like a balloon filled with water in adults with popliteal cyst. When the cyst is large, it would cause discomfort or stiffness ${ }^{[1,2]}$. X-ray examination showed a spherical soft tissue shadow at the popliteal space and viscous liquid could be extracted by puncture. Once the disease recurs, it will severely affect the normal joint function, lasting for a long time. For those with large cysts, surgical treatment should be performed in time. Traditional surgery for the treatment of popliteal cyst shown in fig. 1, usually begins with posterior approach and the entire cyst is resected in an open and direct view. However, there is still high recurrence rate and unsatisfactory outcome ${ }^{[3,4]}$. With the development of the

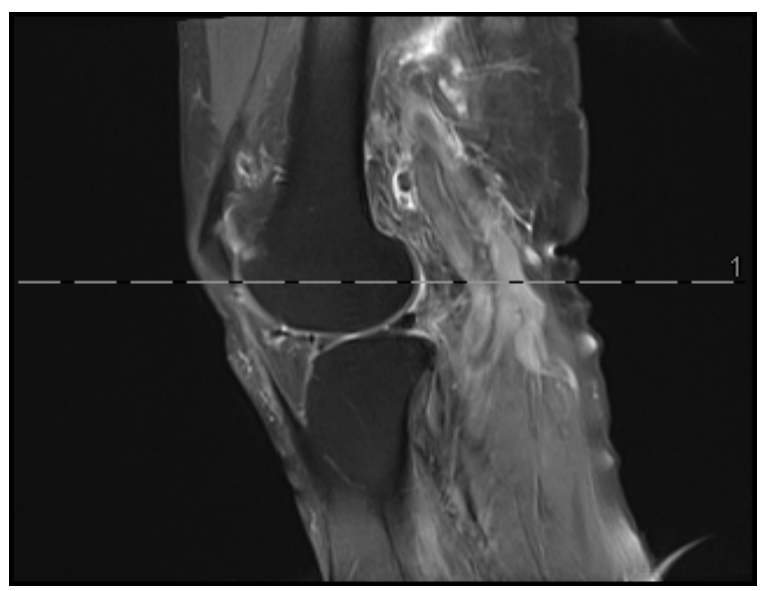

Fig. 1: Image of a popliteal cyst research, arthroscopy-assisted modified approach in the resection of popliteal cyst yields better results, which not only reduce the source of synovial fluid by treating the primary lesions in the joint, but also significantly improves clinical outcomes. Using promethazine to produce a local block at the same time can minimize the recurrence rate.

The present study was carried out to analyze this issue, which is as follows. A total of 116 patients definitely diagnosed with popliteal cyst (fig. 2) and treated at Fuzhou General Hospital of Nanjing Military Command from January 2015 to June 2017 were enrolled. All patients enjoyed the right to know and formal consent forms were obtained. This study was approved by the ethic committee of this hospital. The patients were randomized into the research group and the control group, with 58 patients in each group. Of those, there were 30 males and 28 females in the research group, with an average age of $48.9 \pm 3.2 \mathrm{y}$. There were 32 males and 26 females in the control group, with an average age of $46.8 \pm 3.5 \mathrm{y}$. Data obtained from both groups was comparable.

The patients in the control group were treated with routine surgery. That is, the patient was placed at a prone position and an " $\mathrm{S}$ " incision was made in the popliteal space. Then the cyst was separated from the surrounding tissue layer by layer and the cyst wall was completely resected. The patient was bandaged after operation. On the other hand patients in the research group had local block with promethazine and underwent arthroscopyassisted modified popliteal cyst resection. The main procedure followed was, full preparation before surgery, 
routine disinfection was performed and an aseptic perforated towel was placed. General anesthesia or spinal and epidural anesthesia was adopted and correct supine position was maintained. A balloon tourniquet was placed at the upper and middle part of the thigh. The anterior-lateral and anterior-medial approach was utilized, a $30^{\circ}$ lens was used and the knee joint was probed. Arthroscopic partial meniscus resection, total joint synovectomy or debridement for osteoarthritis were performed ${ }^{[5]}$. After that, the lens enters the posterior medial space through the intercondylar approach. With the help of posterior medial approach, as well as the synovial planer tool and probe, the opening of the bursa mucosa of the gastrocnemius muscle semi-membrane muscle was found in the folds of joint capsule behind the medial condyle of femur. The crack was cut open with radiofrequency and a synovial planer tool. The one-way valve tissue at the traffic port was cut off, through which yellow viscous sac fluid overflows freely into the joint. Then $70^{\circ}$ lens was used. Multilocular sac with fibrous septa and the chondroma inside was observed. The sac cavity was explored with the planer

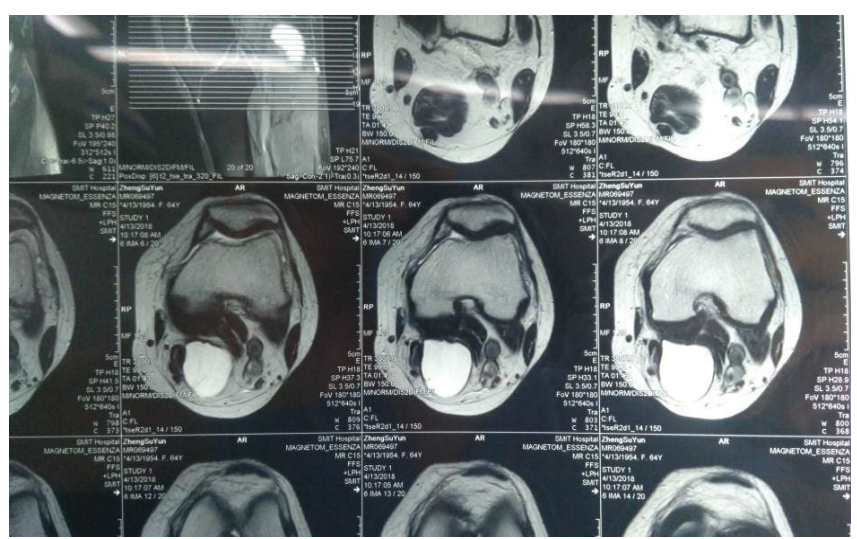

Fig. 2: The images of popliteal cyst in a patient

TABLE 1: COMPARISON OF THE SURGICAL TIME AND INCISION LENGTH BETWEEN BOTH GROUPS

\begin{tabular}{lccc}
\hline Group & Cases & $\begin{array}{c}\text { Incision length } \\
(\mathbf{c m})\end{array}$ & $\begin{array}{c}\text { Surgical time } \\
(\mathbf{m i n})\end{array}$ \\
\hline Research group & 58 & $1.06 \pm 0.11$ & $18.93 \pm 1.46$ \\
Control group & 58 & $10.09 \pm 0.28$ & $25.88 \pm 1.59$ \\
$t$ & & 9.25 & 6.73 \\
$P$ & & $<0.05$ & $<0.05$ \\
\hline
\end{tabular}

tool passing through the enlarged opening on posterior medial approach. The fibrous septa were resected and the chondroma was removed. The inner synovial tissue of the cystic wall of the popliteal cyst was removed, while the outer wall of the cyst was kept intact. When the synovial layer was removed, routine drainage was performed ${ }^{[6]}$.

The length of surgical incision and surgical time of both groups were recorded. Also, the recovery rate and recurrence rate were evaluated according to the classification method of popliteal cyst. Meanwhile, the remission rates of clinical symptoms $2 \mathrm{~d}, 1 \mathrm{mo}, 2 \mathrm{mo}$ and $1 \mathrm{y}$ after operation and the magnetic resonance imaging data were observed and compared. Statistical analysis was performed using SPSS21.0. All quantitative data were expressed in the form of mean \pm standard deviation and comparisons were made with t-test. Enumeration data were expressed in the form of natural number (n) + percentage $(\%)$, and comparisons were made with chi-square test. $P<0.05$ represented the intergroup difference was of statistical significance.

As shown in Table 1, the incision length and surgical time of the research group were significantly less than that of the control group $(P<0.05)$. As shown in Table 2 , based on the Rauschning and Lindgren classification method of popliteal cyst, results showed that the recovery rate and recurrence rate of the research group were better than that of the control group. The details were listed in Table 3. The clinical symptom remission rates of the research group $2 \mathrm{~d}$ after operation was 86.21 $(50 / 58)$, which is significantly higher than that of the control group $60.34(35 / 58)(P<0.05)$. The MRI image data $1 \mathrm{mo}, 2 \mathrm{mo}$, and $1 \mathrm{y}$ after operation demonstrated superior recovery in the research group (fig. 3 ) over the control group $(P<0.05)$.

Promethazine, an antihistamine is a phenothiazine derivative and subcutaneous injection of promethazine can produce local necrotic lesions due to chemical stimulation. With full utilization of this principle ${ }^{[7]}$, local block with promethazine for the treatment of popliteal cysts yields better therapeutic outcome. Moreover, there are advantages like less pain and trauma, no surgical scars and no effect on appearance

TABLE 2: THE RAUSCHNING AND LINDGREN CLASSIFICATION METHOD OF POPLITEAL CYST

\begin{tabular}{|c|c|c|c|c|}
\hline Classification & Grade 0 & Grade I & Grade II & Grade III \\
\hline Indicators & $\begin{array}{l}\text { No swelling or pain, no } \\
\text { limited activities }\end{array}$ & $\begin{array}{l}\text { Slightly swelling or } \\
\text { feeling of tension in the } \\
\text { popliteal space after } \\
\text { strenuous exercises, } \\
\text { slightly limited activities }\end{array}$ & $\begin{array}{c}\text { Swelling or pain } \\
\text { after normal activity, } \\
\text { activities limited less } \\
\text { than } 20^{\circ}\end{array}$ & $\begin{array}{c}\text { Swelling or pain at rest, } \\
\text { activities limited more } \\
\text { than } 20^{\circ}\end{array}$ \\
\hline
\end{tabular}


TABLE 3: THE RECOVERY RATES OF GRADE 0 AND RECURRENCE RATES OF BOTH GROUPS

\begin{tabular}{lccc}
\hline Group & Cases & The recovery rate of Grade 0 & The recurrence rate \\
\hline Research group & 58 & $51(87.93)$ & $2(3.45)$ \\
Control group & 58 & $41(70.69)$ & $8(13.79)$ \\
$\mathrm{t}$ & & 6.20 & 5.41 \\
$\mathrm{P}$ & & $<0.05$ & $<0.05$ \\
\hline
\end{tabular}

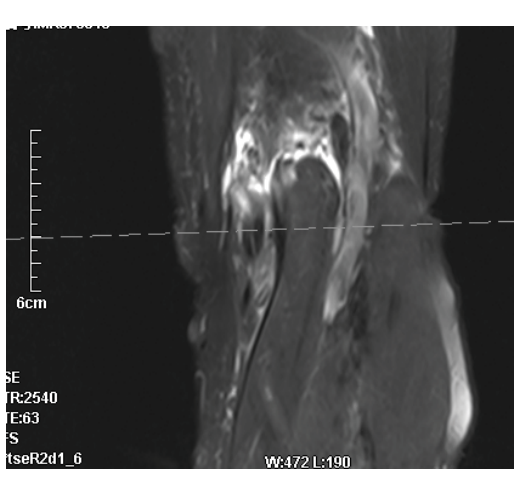

A

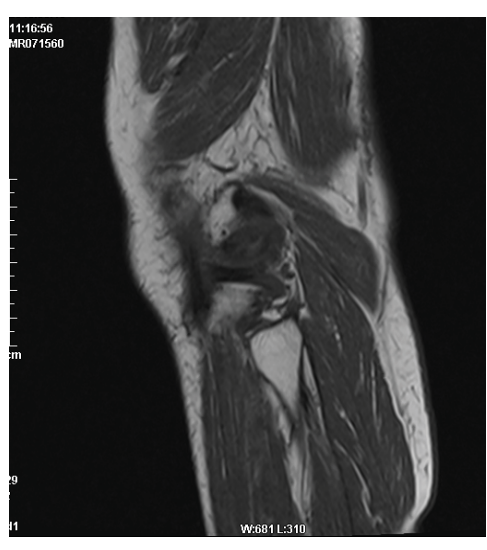

B

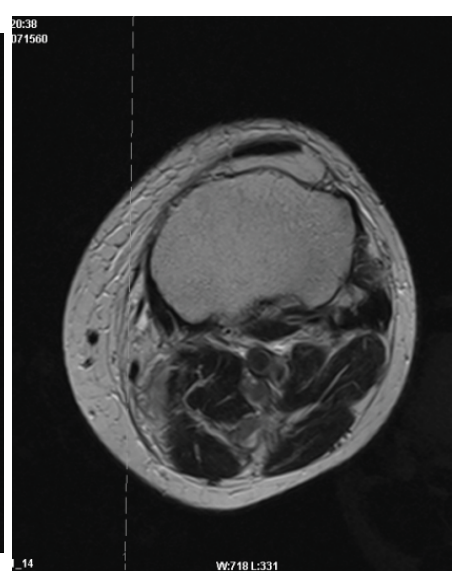

C

Fig. 3: MRI images of a patient after surgery

MRI image data A. 1 month after, B. 2 months after and C. 1 year after operation

and a simple procedure. Therefore, the application worked well. The patients in the research group were treated with modified popliteal cyst resection. When the one-way valve was removed, the planer was drilled through the posterior medial approach and the fibrous septa and inner synovial membrane were selectively resected. When cleaning the fibular side of inner layer of the cyst, care must be exercised and clean with gentle sweeping ${ }^{[8]}$. The inner loose synovial membrane was dissected. The depth of the planer is strictly controlled under arthroscopy to prevent penetrating the outer capsule. By opening the crack of the bursa mucosa of the gastrocnemius muscle semi-membrane muscle and dissecting the one-way valve, the unidirectional circulation is turned into a two-way circulation, which can not only treat primary lesions in the joint, reduce the production of synovial fluid, but also significantly improve the therapeutic outcome and reduce the recurrence rate.

Local block with promethazine and arthroscopyassisted modified popliteal cystresection was applied on patients of the research group. Results showed the incision length and surgical time of the research group were significantly less than that of the control group $(P<0.05)$. The remission rates of clinical symptoms 2 $\mathrm{d}, 1 \mathrm{mo}, 2 \mathrm{mo}$ and $1 \mathrm{y}$ after operation, the MRI image data, the recovery rate and recurrence rate, all indicated that the research group had greater advantage over the control group $(P<0.05)$. The above findings fully demonstrate the efficiency of this regimen, which is in line with published studies ${ }^{[9-13]}$.

To sum up, local block with promethazine could exert ideal outcomes in the treatment of popliteal cyst than routine surgery. Also, arthroscopy-assisted modified popliteal cystresection significantly improved therapeutic outcome. Moreover, it should be noted that during the arthroscopic separation of the cyst, the corresponding procedure must be carried out in direct view. The vascular nerve and the surrounding tissue should be carefully identified. Blind application of the electric planer and RF vaporization is prohibited to prevent damage of the vascular nerve. However, this study has limitations. For example, the sample size is small, and larger study should be conducted in the future. Also, there is no group study for patients with combined intra-articular diseases, and the size of the popliteal cyst is usually closely related to the patient's recent activities. In this study, MRI showed that some popliteal cysts were smaller or even disappeared in some patients one year after surgery, which was related to the curative effect of arthroscopic surgery itself, or related to the change of activity behavior habits. It is remained to be demonstrated.

\section{Acknowledgements:}

Science and Technology Project in Putian City - Clinical study of arthroscopic modified popliteal cyst resection (No. 2018SJ3003) 


\section{REFERENCES}

1. Jiang HB, Bai LH, Li B, Li D, Su YL. Clinical analysis of arthroscopic treatment of popliteal cyst. Chin J Bone Joint 2017;2(12):674-6.

2. Li HF, Ruan DK. Progress in diagnosis and treatment of popliteal cyst after total knee arthroplasty. Chin J Bone Joint 2018;2(12):691-3.

3. Zhao Y. Treatment of 35 cases of popliteal cyst with anterior arthroscopy guided by methylene blue. Zhejiang Medical Association Osteoscience Branch, Zhejiang Medical Doctor Association Orthopaedic Branch. 2016 Zhejiang Provincial Orthopaedic Academic Annual Conference. Zhejiang Medical Association Osteoscience Branch, Zhejiang Medical Doctor Association Orthopaedic Branch.

4. Wilmot I, Constance CE, Cassedy A, Kudel I, Bradley MS, John JL. Health-related quality of life in children with heart failure as perceived by children and parents. Cardiol Young 2016; 26(5):340-8.

5. Reiner B, Robert DR. Editorial (Thematic Issue: The Long Way to a Successful Medical Therapy of Heart Failure with Beta-blockers in Children with Heart Disease). Rev Recent Clini Trials 2014;9(2):206-13.

6. Wu LC. Clinical analysis of arthroscopic GSB enlarged internal drainage wall removal for treatment of popliteal cyst. Zhejiang Medical Association Osteoscience Branch. 2015 Zhejiang Provincial Orthopaedic Academic Annual Conference Papers - Joint Topics. Zhejiang Medical Association Osteoscience Branch 2015;(01).

7. Guo L. Arthroscopic posterior chamber valvulotomy combined with cyst wall dissection for the treatment of popliteal cyst. Chinese Society of Integrated Traditional and Western Medicine, Department of Orthopaedics and Traumatology.
Compilation of the 24th Annual Meeting of Chin J Integrated Traditi Western Med 2017;(01).

8. Kachaporn N, Win T. Congestive heart failure in children with pneumonia and respiratory failure. Pediatr Int 2017;59(3):126068.

9. Peng W, Li D, Zhang M, Ge S, Mo B, Li S, et al. Characteristics of antibacterial molecular activities in poplar wood extractives. Saudi J Biol Sci 2017;24(2):399-404.

10. Khan A, Mehmood S, Khan N, Khan RA. Cytotoxic activities of rosa brunonii, calligonum polygonoides, pegnum harmala and sueda fruticosa extract using brine shrimp. Pak J Pharm Sci 2017;30(6):2281-4.

11. Daniela I, Angela B, Daniel-Corneliu L, Gabriel S, Diana D, Iulia L. Evaluation of NT-proBNP in children with heart failure younger than 3 years old. Rom J Intern Med 2017;55(2):560-6.

12. Kuti B, Oyelami A. Childhood community-acquired pneumonia at the wesley guild hospital, Ilesa: Prevalence, pattern, and outcome determinants. Niger J Health Sci 2015; 15(2):125-131.

13. Kumari N, Rana RC, Sharma YP, Kumar S. Extraction, purification and analysis of sweet compounds in stevia rebaudiana bertoni using chromatographic techniques. Indian J Pharm Sci 2017;79(4):617-24.

This is an open access article distributed under the terms of the Creative Commons Attribution-NonCommercial-ShareAlike 3.0 License, which allows others to remix, tweak, and build upon the work non-commercially, as long as the author is credited and the new creations are licensed under the identical terms

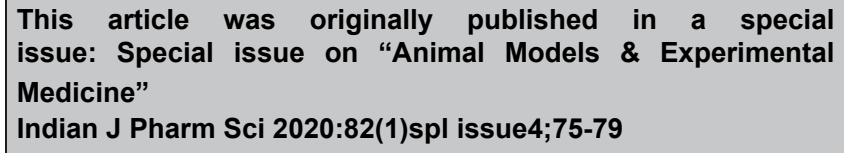

